\title{
Educação inclusiva em tempos de pandemia: assistência aos estudantes da educação especial por meio da educação remota
}

\author{
Inclusive education in times of pandemic: assisting special education \\ students through remote education
}

Gilda Fernandes Silva Rocha Licenciada em Pedagogia Universidade Federal de Ouro Preto - UFOP. Ouro Preto, MG - Brasil. gildafernandes@live.com

Márcia de Freitas Vieira

Doutora em Educação Professora Formadora UAB Universidade Federal de Ouro Preto - UFOP. Ouro Preto, MG - Brasil marcia.ipatinga@gmail.com

\begin{abstract}
Resumo: A pandemia de COVID-19 provocou muitas mudanças no contexto social, inclusive a necessidade do isolamento e distanciamento social. As escolas precisaram inovar para que a educação não fosse interrompida. Os governos estaduais adotaram a Educação Remota Emergencial. Essa modalidade de ensino trouxe mais dificuldades de acesso à educação para os estudantes da Educação Inclusiva. A realidade dos estudantes público-alvo da Educação Especial, nesse cenário de ensino remoto, norteou o desenvolvimento de uma pesquisa de revisão bibliográfica com o objetivo de compreender como os estudantes de educação inclusiva estão sendo assistidos durante o período da pandemia. Os resultados destacam que a falta de acesso tecnológico dificultou muito o alcance desses estudantes ao ensino remoto. Por outro lado, a pandemia possibilitou uma colaboração maior entre a família e a escola, fato esse enriquecedor para o público-alvo da educação especial, que conta com mais apoio da família no processo de ensino-aprendizagem.
\end{abstract}

Palavras chave: educação inclusiva; ensino remoto; pandemia de COVID-19.

Abstract: The COVID-19 pandemic caused many changes in the social context, including the need for isolation and social distance. Schools needed to innovate so that education was not interrupted. State governments have adopted Remote Emergency Education. This type of teaching brought more difficulties in accessing education for Inclusive Education students. The reality of students target audience of special education, in this remote education scenario, guided the development of a literature review research with the aim of understanding how inclusive education students are being assisted during the pandemic period. The results highlight that the lack of technological access made it very difficult for these students to reach remote learning. On the other hand, the pandemic has enabled greater collaboration between the family and the school, which is enriching for the target audience of special education, which has more support from the family in the teaching-learning process.

Key-words: inclusive education; remote teaching; COVID-19 pandemic.

Cite como

\section{(ABNT NBR 6023:2018)}

ROCHA, Gilda Fernandes Silva; VIEIRA, Márcia de Freitas. Educação inclusiva em tempos de pandemia: assistência aos estudantes da educação especial por meio da educação remota. Dialogia, São Paulo, n. 39, p. 1-14, e20600, set./dez. 2021. Disponível em: https://doi.org/10.5585/39.2021.20600.

American Psychological Association (APA)

Rocha, G. F. S., \& Vieira, M. de. F. (2021, set./dez.) Educação inclusiva em tempos de pandemia: assistência aos estudantes da educação especial por meio da educação remota. Dialogia, São Paulo, 39, p. 1-14, e20600. https://doi.org/10.5585/39.2021.20600. 


\section{Introdução}

Este artigo foi elaborado em um momento em que o mundo e a educação vivenciam um cenário assustador. As escolas estão fechadas desde março de 2020, decorrente do surgimento de uma pandemia que ainda amedronta o mundo inteiro (VIEIRA e SECO, 2020). Devido a sua alta taxa de transmissão e à ausência de vacinas e tratamentos efetivos, a COVID-19 provocou o isolamento social e, consequentemente, a interrupção das aulas presenciais.

A escola é um espaço onde há grandes trocas e mobilidades de pessoas de várias faixas etárias, sendo, portanto, um dos locais com grandes probabilidades de contaminação e propagação do vírus, o que vem a colocá-la como um dos últimos espaços a serem reabertos (ARRUDA, 2020).

Tudo era novo, as aulas haviam se iniciado em fevereiro de 2020, turmas novas, professores novos e um novo vírus. O vírus foi descoberto na China em dezembro de 2019. Em janeiro de 2020, as autoridades e a Organização Mundial da Saúde (OMS) anunciaram que uma série de casos de pneumonia surgiram provocados pelo novo Coronavírus.

Segundo Werneck e Carvalho (2020), a pandemia da COVID-19 é um dos maiores desafios sanitários enfrentados. A transmissão da doença entre humanos, sua capacidade de mutação e transmissão pelas vias respiratórias, permite que ela se propague de maneira mais fácil. Na China, medidas foram tomadas na tentativa de bloquear a transmissão do vírus, vôos cancelados, fronteiras fechadas, mas o vírus se espalhou para outros países além das fronteiras desse país.

No Brasil, o primeiro caso foi confirmado em fevereiro de 2020. O vírus se disseminou rapidamente e inúmeras restrições foram criadas para tentar conter o avanço. Os governos federais e estaduais determinaram o fechamento das escolas como uma ação de prevenção contra a propagação do vírus, uma medida radical e necessária (FACHINETTTI; SPINAZOLA; CARNEIRO, 2021).

O isolamento social era a maior defesa contra o vírus, trazendo assim impactos econômicos severos. Inúmeros setores foram obrigados a parar. E com a educação não foi diferente. Embora crianças e jovens fizessem parte de um grupo de faixa etária menos propícia à doença, estavam em contato direto e diário com grupos de risco, idosos e portadores de doenças respiratórias (ARRUDA, 2020).

Com as escolas fechadas, a grande preocupação dos dirigentes educacionais, professores e estudantes seria como dar continuidade aos estudos. Conforme Vieira e Seco (2020, p.1027) “A pandemia por COVID-19 obrigou as instituições educacionais e os professores, em nível mundial, a alterar drasticamente as suas práticas educativas". 
A modalidade de Educação a Distância $(\mathrm{EaD})$ no Brasil já era uma realidade entre as instituições de graduação e pós-graduação. E neste contexto pandêmico, se tornou uma opção também para os níveis de ensino fundamental e médio. Segundo Arruda (2020), a COVID-19 se espalhou em alta velocidade pelo mundo, imediatamente levando $90 \%$ da população estudantil a se isolar. Não havendo outra solução devido à emergência do isolamento social, o Brasil adotou a Educação Remota Emergencial, porém, o acesso às tecnologias digitais na educação pública é precário.

\begin{abstract}
No Brasil apresenta-se propostas difusas, que refletem a falta de liderança do Ministério da Educação, que indicou a possibilidade de se utilizar a modalidade a distância no ensino superior, por meio da portaria n. 343 de 2020, posteriormente apresentou a medida provisória n. 934 que retirou a obrigatoriedade de cumprimento de 200 dias letivos, mantendo a carga horária mínima nos diferentes níveis educacionais. A tomada de decisões a respeito do modelo de funcionamento da educação básica ficou sob os cuidados dos estados que têm apresentado iniciativas que se direcionam à substituição da educação presencial pelas aulas remotas ou adoção da modalidade a distância na educação básica (ARRUDA 2020, p. 261-262).
\end{abstract}

Cabe ressaltar aqui, que "as experiências de aprendizagem online bem planejadas são significativamente diferentes do ensino remoto que tem sido adotado pelas instituições educacionais em resposta à crise gerada pela COVID-19” (VIEIRA; SECO, 2020, p. 1015). A educação remota emergencial assemelha-se à $\mathrm{EaD}$ somente no que tange à prática de uma educação mediada pela tecnologia digital, seguindo os mesmos princípios da educação presencial, com o modelo expositivo tradicional no qual o aluno é mero repositório de informações (JOYE et al., 2020).

No Brasil, o decreto n ${ }^{\circ}$ 9.057/2017 no artigo 1 caracteriza a educação a distância, como:

modalidade educacional na qual a mediação didático-pedagógica nos processos de ensino e aprendizagem ocorra com a utilização de meios e tecnologias de informação e comunicação, com pessoal qualificado, com políticas de acesso, com acompanhamento e avaliação compatíveis, entre outros, e desenvolva atividades educativas por estudantes e profissionais da educação que estejam em lugares e tempos diversos (BRASIL, 2017).

Diferentemente da $\mathrm{EaD}$, a educação remota emergencial envolve o uso de soluções de ensino totalmente remotas para as aulas previamente elaboradas no formato presencial (Hodges et al., 2020), e caracteriza-se pela disponibilização de videoaulas gravadas, aulas online e compartilhamento de materiais digitais em plataformas online (Arruda, 2020).

Autores como Grossi, Minoda e Fonseca (2020) afirmam que o impacto da COVID-19 na educação é irreversível. Segundo os autores, $87 \%$ da população estudantil mundial foram afetadas com a suspensão das aulas. As instituições têm enfrentado muitas dificuldades ao oferecer o ensino remoto, desde a adequação do conteúdo e apoio aos professores à orientação e acompanhamento 
das famílias. No entanto, a adaptação de professores e estudantes a essa nova modalidade de ensino é necessária, já que não se sabe muito sobre o vírus, seu fim e mutações (ARRUDA 2020).

Sabe-se desta maneira que a situação trazida pela pandemia perdura por meses e não terá fim tão cedo. Um vírus que outrora, não era letal para crianças e adolescentes, tem mostrado o contrário e vem fazendo suas vítimas. Meireles et al. (2020) afirma que os efeitos indiretos (saúde mental) da pandemia podem ser maiores que os efeitos diretos. No Brasil, desde março de 2020, cerca de 800 crianças de até 12 anos morreram por causa do vírus, o que indica que, talvez, a retomada ao ensino presencial não ocorrerá brevemente.

Neste contexto e sabendo-se que são grandes as dificuldades no atendimento ao estudante da educação especial, uma vez que não há investimentos públicos suficientes em profissionais, em material didático e em estrutura física das escolas, buscou-se, por meio de uma pesquisa de revisão bibliográfica, responder as seguintes questões: como o estudante público-alvo da educação especial tem sido assistido neste momento? Sabendo-se que o contato entre professor e aluno é um dos pontos mais importantes para o processo de ensino e aprendizagem, como está ocorrendo o progresso na aprendizagem das crianças e no trabalho do professor visto que esse contato tem sido evitado?

Os desafios referentes à inclusão escolar são inúmeros no Brasil. Entre esses, podemos citar a preparação do corpo docente, as condições para que haja êxito na execução de um projeto pedagógico inclusivo, a estrutura física das escolas, os cursos de formação para os profissionais da educação especial, os recursos materiais, instrumentais, entre outros (FACHINETTI; SPINAZOLA; CARNEIRO, 2021).

Como se não bastassem tantas barreiras, o isolamento social dificulta ainda mais o acesso dos profissionais da educação ao estudante da educação especial. Nesse tempo, as dificuldades surgem com força maior. Na literatura acadêmica encontram-se vários artigos e outras publicações que tratam a educação em tempos de pandemia de forma geral, mas pouco se fala sobre a atenção específica ao público-alvo da educação especial.

Assim, objetivou-se por meio desse trabalho, compreender como o estudante público-alvo da educação especial tem sido assistido por meio da educação remota; o que tem sido feito para que esses estudantes não retrocedam no processo de ensino e aprendizagem e para que seu desenvolvimento não seja prejudicado. Mesmo que não haja "avanço", como não retroceder? A vacina "chegou", mas até que todos estejam vacinados e que seja possível retomar o ensino presencial, ainda viveremos um longo período de isolamento social. 
Esta pesquisa buscou ainda, descobrir alternativas para os desafios encontrados pelos professores e estudantes da Educação Especial Remota, tais como: conteúdo acessível, participação dos estudantes, garantia de assistência de profissionais do Atendimento Educacional Especializado (AEE), planejamentos diários, opções que darão continuidade ao processo de ensino e aprendizagem.

Diante do exposto, este artigo tem como foco principal, o aprendizado do estudante público-alvo da educação especial no período de pandemia, ressaltando a situação atual decorrente do isolamento social e também, como será o retorno presencial para esses estudantes e as dificuldades que enfrentarão. Em primeira instância, esse artigo identifica as dificuldades encontradas durante o ensino remoto para o estudante público-alvo da educação especial; posteriormente, o papel da escola diante do exposto e, por fim, o retorno à educação presencial para os mesmos. A seguir, são discutidos os resultados da pesquisa e tecidas as considerações finais do estudo.

\section{Estudantes da educação especial e a pandemia de COVID-19}

A Organização Mundial da Saúde (OMS) alerta sobre a pessoa com deficiência, o quanto sofrerá ainda mais com esse processo de ensino remoto e isolamento social. Professores e estudantes não estavam preparados para a educação online e as dificuldades de adaptação são inúmeras.

As pessoas com algum tipo de deficiência ainda enfrentam nos dias atuais o preconceito. Quais são as consequências do isolamento social para o estudante público-alvo da educação especial? Aqueles que há tempos já vivem isolados devido à falta de acesso urbanístico, estrutura física, dificuldade de comunicação, falta de tecnologia assistiva, infelizmente percebe-se que novamente essas pessoas foram mais prejudicadas e estão à mercê dessa situação (CURY et al., 2020).

A Educação Inclusiva relaciona-se ao acesso e permanência de todos os estudantes na escola. O estudante da educação especial precisa do professor de apoio, que em conjunto ao professor da turma regular, proporcionará atividades de acordo com cada individualidade, atuando assim também no ensino remoto. Esforços têm ocorrido para que barreiras sejam identificadas e ultrapassadas no processo de ensino e aprendizagem, buscando-se adaptações e apoio de forma individual em tempos de pandemia, levando em consideração aspectos intelectuais, acadêmicos e também habilidades sociais; tendo em vista suas especificidades (MARCOLLA et al., 2020). 
O Atendimento Educacional Especializado, mais conhecido como AEE, viabiliza identificar, organizar e elaborar recursos que rompam as barreiras que dificultam a participação dos estudantes, levando em consideração suas dificuldades específicas. Segundo Cury et al. (2020), o trabalho do AEE não se restringe apenas às salas de aula. $O$ trabalho do AEE articulado às circunstâncias de ensino remoto pode auxiliar professor e estudante a desenvolverem seus trabalhos durante a pandemia. Inúmeras são as possibilidades oferecidas por esses autores para que haja assistência a esses estudantes.

O contato com profissionais e professores de maneira online é importantíssimo, mantém o vínculo social com os estudantes da educação especial, fazendo assim com que possam se sentir pertencentes a esse ambiente, não só presencialmente. Os recursos pedagógicos e tecnológicos utilizados no AEE juntamente com os profissionais da educação e também articulados ao trabalho realizado pelo professor da sala de aula, possibilitam planejar e desenvolver atividades para serem enviadas aos estudantes da educação especial, proporcionando um aprendizado significativo.

Envolver os estudantes em confecções de recursos lúdicos pedagógicos, utilizar os boletins informativos na linguagem dos estudantes para assim os abranger, fazendo com que os mesmos e seus familiares compreendam a situação enfrentada e possam entender como se prevenir contra o vírus. É fundamental um acompanhamento frequente ao público-alvo da educação especial nesse período e necessário que haja um canal direto com a família de acordo com cada necessidade, possibilitando momentos de "tutoria individual" (CURY et al., 2020).

O diálogo entre a escola, os pais e os filhos é peça fundamental (BEZERRA; ARRUDA; SILVA, 2020). Quando o professor não recebe o retorno das famílias, a situação se complica, pois, essa é uma das poucas formas de se perceber os resultados, já que não há o contato direto entre professor e estudante.

É sabido que há uma escassez de profissionais qualificados para atuar na área da Educação Especial Inclusiva. Agora, a busca é por profissionais qualificados para atuar na área da Educação Especial Inclusiva em tempos de pandemia e ensino remoto. Se para o professor já era difícil trabalhar com 20 estudantes reunidos em sala de aula, com assistente para o público-alvo da educação especial, o "cada um na sua casa” dificultou ainda mais essa realidade.

Graças às tecnologias digitais de informação e comunicação (TICs), o contexto atual oferece opções e possibilidades opostas às pandemias enfrentadas no contexto passado. Porém, mesmo com toda evolução da tecnologia e internet, encontram-se desafios como a dificuldade de prender a atenção dos estudantes e tornar a educação online um ambiente de interação, ou seja, ela é desafiadora (ARRUDA, 2020). 


\section{Estudantes da educação inclusiva, o direito à educação}

A lei de $n^{0} 9.394$ - Lei de Diretrizes e bases da educação nacional (LDB) estabelece a educação especial como assistencial aos estudantes com necessidades educacionais especiais. Aprovada em dezembro de 1996, essa lei assegura o direito de toda a população a uma educação gratuita e de qualidade (BRASIL, 1996).

O ensino remoto não foi planejado e estruturado pelos governos estaduais e/ou municipais; ele surgiu de maneira repentina, por causa de um problema de saúde que afetou o mundo inteiro. O público-alvo da educação especial pode ser afetado ainda mais com esse processo. As dificuldades de adaptações para estudantes e professores, no geral, encontram diversas barreiras, dentre elas o acesso e a infra-estrutura. Para o estudante com necessidades educacionais especiais as barreiras são ainda maiores, trazendo assim enorme evasão e desigualdade (MARCOLLA et al., 2020).

A socialização, um dos pontos chaves para o desenvolvimento dos estudantes da educação especial e para inclusão, foi a primeira a ser restrita com o isolamento social. Levou os estudantes a retrocederem para "seu mundo separado" e viver novamente isolado (CURY et al., 2020).

O Art. 227 da Constituição Federal (BRASIL, 1988) assegura que é dever da família, da sociedade e do Estado garantir à criança, jovem e adolescente, o direito à vida e à saúde, assim como à educação, porém, vida e saúde são primordiais. O novo Coronavírus ameaça a vida e a saúde de toda comunidade escolar. No entanto, o retorno ao ensino presencial será possível quando a ameaça à vida e à saúde não mais existir.

O artigo 205 da Constituição Federal garante um sistema educacional inclusivo, trazendo ao estudante de educação especial direitos para exercer a educação, e acesso aos recursos necessários para a excelência no ensino aprendizagem (BRASIL, 1988). Em tempos de Pandemia não é diferente. Os estudantes da educação especial precisam ser assistidos e, mesmo de maneira remota, receber assistência total para que possam se desenvolver educacionalmente. Em 6 de julho de 2015, foi estabelecida a Lei de $n^{0} 13.146$, designada a assegurar e promover em igualdade, o exercício de direitos e liberdades elementares às pessoas com necessidades especiais, tendo em vista a inclusão social e cidadania (BRASIL, 2015).

Diante do cenário pandêmico, o acesso ao público-alvo da educação especial deve ser uma busca constante. A propósito, o $\int \mathrm{I}$ do Art. 28 da Lei de $\mathrm{N}^{0} 13.146$ garante um sistema educacional inclusivo, independente dos níveis e modalidades (BRASIL, 2015). As tecnologias de informação podem amparar essas buscas dando suporte a esse acesso entre professor, família e estudante. As 
TICs possibilitam a informação e comunicação, proporcionam o compartilhamento de conhecimentos trazendo à tona um grande universo de saberes (MARCOLLA et al., 2020).

3 O papel da escola para a efetivação da inclusão frente à pandemia da COVID-19 e o retorno presencial para os estudantes portadores de necessidades especiais

Segundo Cury et al. (2020) a pandemia trouxe a queda da rotina e revelou a desigualdade existente na sociedade, na educação e no acesso tanto à informação quanto à tecnologia. Com o fechamento das escolas, buscaram-se alternativas para desenvolver um ensino remoto inclusivo.

Simões (2020) ressalta a dificuldade dos estudantes surdos para se "encaixarem" nessa educação remota emergencial. Na pesquisa realizada pela autora, estes foram os mais afetados por não possuírem acesso às tecnologias. Condições sociais, linguísticas e cognitivas desses estudantes deixaram de ser avaliados. Estudantes esses que foram "forçados" a se submeterem a esse novo modelo de ensinar e aprender.

Fachinetti, Spinazola e Carneiro (2021) abordam as dificuldades da educação especial como a falta de recursos materiais, instrumentais, humanos, assim como a devida formação docente dando base às mudanças que envolvem toda comunidade escolar. Como todo o corpo estudantil, foi preciso que a educação especial inclusiva se adaptasse buscando alcançar a escola e a família devido à interrupção das aulas presenciais.

O ensino remoto trouxe desafios tanto para os professores quanto para os estudantes, devido à falta de acesso e domínio da tecnologia para ambos (VIEIRA e SECO, 2020). O ensino por meio da tecnologia foi a saída encontrada pelas escolas para darem segmento ao processo educacional. Porém, embora sejam evidentes as dificuldades, o ensino remoto em tempos de pandemia foi uma grande assertiva feita pelas instituições de ensino.

Dessa forma, investimentos na formação de professores, especialmente daqueles que não possuem o domínio da tecnologia, assim como o fornecimento de computadores aos estudantes de famílias de baixa renda, também seriam assertivas. Juntamente com a coordenação das escolas, o governo poderia criar e oferecer pacotes que dessem acesso gratuito a internet, onde dados pessoais permitissem esse alcance, podendo, dessa maneira, permitir que essa conexão à tecnologia de certa forma incluísse aquele que não tem condições de aquisição (FACHINETTI; SPINAZOLA; CARNEIRO, 2021).

Gonçalves e Ferreira (2020) citam práticas educacionais inclusivas que permitem a continuidade dos trabalhos realizados com os estudantes da educação especial, mesmo na 
modalidade de ensino remoto. Os recursos digitais e o universo virtual proporcionam a formação de leitores digitais, podendo incentivar esses estudantes em sua leitura e escrita diante da educação remota.

Essas práticas viabilizam prosseguir com o ensino inclusivo de modo a não permitir que os estudantes de educação especial retrocedam ou tenham seu desenvolvimento prejudicado. Assim as tecnologias permitem a aproximação entre as pessoas e ações coletivas que outrora eram impensáveis. Tais ações coletivas favorecem a integração do estudante público-alvo da educação especial ao espaço escolar.

Se o ensino remoto trouxe grandes desafios para os estudantes da educação especial, a volta ao ensino presencial não colocará fim às mesmas. $\mathrm{O}$ direito ao retorno presencial é de todos os estudantes, assim como o acesso à educação. O retorno ao ensino virá dotado de desafios, desde os aspectos estruturais e organizacionais da escola, que deverá estar de acordo com os protocolos, até os aspectos emocionais dos estudantes, professores e familiares. Novos desafios, novas estratégias para reinvenção das relações afetivas e desenvolvimento do trabalho pedagógico (FRANCO et al, 2020).

O processo de socialização será “reiniciado”. Um público que outrora era impossibilitado de conviver em sociedade devido a suas limitações foi obrigado a se "fechar" novamente em conseqüência do isolamento social. O retorno ao ensino presencial trará necessidades além de físicas, psicológicas. Nesse momento é importante que se priorize o acolhimento. Ouvir os estudantes facilitará o planejamento pedagógico individualizado e o atendimento de acordo com suas necessidades educacionais específicas. Desta forma, oferecendo condições de acesso e permanência de maneira igualitária ao sistema de ensino (CURY et al., 2020).

\section{Metodologia}

Este estudo foi desenvolvido através de uma pesquisa de revisão bibliográfica. Predominando-se a pesquisa qualitativa, permitiu uma visão mais ampla a respeito da situação enfrentada pelos estudantes da educação especial diante da educação remota emergencial.

Fontes e Poleto (2017) relatam a importância da pesquisa científica, trazendo-a como uma forma de realização de um estudo planejado. Desta forma, apresentam a pesquisa qualitativa bibliográfica como sendo um levantamento de dados literários por meio de artigos científicos, livros e publicações em periódicos, fontes utilizadas para elaboração deste mesmo trabalho. O uso da pesquisa de abordagem qualitativa para o desenvolvimento desse trabalho permitiu investigar autores que contribuíram para a produção e apropriação do processo e dos resultados alcançados. 
Iniciou-se o trabalho seguindo as etapas de uma revisão bibliográfica, identificando a pesquisa, selecionando estudos primários, avaliando os estudos, extraindo dados e monitoramentos, fichamentos e sínteses das informações. Por meio desses passos, foi possível encontrar artigos que já discorriam sobre o assunto, deparar e analisar como tem sido a realidade enfrentada pelo público-alvo da educação especial diante da modalidade de ensino remoto emergencial.

\section{Análise e discussão}

Como resultados, se expõem as dificuldades encontradas pelos estudantes da educação especial no modelo de ensino remoto. Os mesmos demandam um método de ensino e aprendizagem que tem dependência do contato físico entre professor e estudante. Compreende-se que durante a educação remota emergencial, a falta de contato próximo com seu tutor e demais colegas terá impacto direto sobre a saúde psicológica do estudante.

Essa modalidade de ensino causou impactos emocionais e psicológicos ao estudante público-alvo da educação especial, porém, contribuiu para que as famílias pudessem estar mais presentes no seu processo de ensino e aprendizagem. A escola passou a ter um pouco mais de apoio das famílias. Este fato poderá contribuir com o desenvolvimento do estudante ao retorno do ensino presencial, onde escola e família terão a oportunidade de trabalhar em conjunto, o que é positivo para maior e melhor desenvolvimento do estudante.

Bem se sabe a precária realidade educacional em nosso país. A pandemia revelou a precariedade ainda maior relacionada às tecnologias assistivas e preparação dos profissionais da área de educação inclusiva, e trouxe à tona a não realidade da educação igualitária para todos, sendo direito e lei, porém não real. No que diz respeito ao direito de educação para todos, sem restrição, não foi algo real mediante ao processo remoto de educação. O público referente aos estudantes e professores de educação inclusiva foi afetado no quesito social e cognitivo devido à falta de políticas públicas inclusivas.

$\mathrm{Na}$ tentativa de minimizar os prejuízos educacionais, alternativas foram adotadas para o ensino remoto em instituições públicas e privadas. No entanto, infelizmente, compreende-se grande falha referente à assistência ao público-alvo da educação especial. A pandemia escancarou ainda mais as dificuldades de inclusão. A falta de acesso às ferramentas utilizadas para webconferência e videoaula alerta para a realidade de limitações já existentes antes mesmo da pandemia, para estudantes cegos, surdos e outras necessidades educacionais específicas (NETA; NASCIMENTO; FALCÃO, 2020). 
Professores tiveram que se adaptar ao cenário de aulas remotas. A adequação dos conteúdos para os estudantes de turmas regulares já veio sobrecarregada de desafios, maiores obstáculos ainda para os estudantes de educação especial. Muitos desses estudantes ficaram excluídos do modelo de ensino remoto por falta de projetos educacionais inclusivos que os ajudariam a lidar melhor com isolamento e a aulas remotas em tempos de pandemia.

Compreende-se que mais uma vez os estudantes da educação especial ficaram prejudicados e de certa forma "não foram incluídos" ao modelo de ensino remoto. Ressalta-se o descaso por parte do Ministério da Educação (MEC) e demais esferas governamentais, responsáveis pela regulamentação de ações referentes à educação brasileira. Desde o fechamento das escolas não houve nenhum projeto que viabilizasse o desenvolvimento dos estudantes da educação especial, ficando sob responsabilidade das próprias instituições escolares a busca por iniciativas e projetos para os alcançarem.

O presente artigo possibilitou a compreensão dos objetivos propostos, mostrando que ainda há grande descaso por parte dos agentes governamentais referente aos estudantes da educação inclusiva. Embora a tecnologia tenha amparado o contato entre os estudantes, professores e famílias, muitos estudantes da educação especial se tornaram inativos ao processo de ensino remoto por não possuírem tecnologias e programas que favorecessem sua inclusão. $\mathrm{O}$ despreparo dos professores também ficou evidente.

As escolas que já possuíam dificuldades se encontraram em situação de maior desespero para lidar com esses estudantes. Desta forma, a menos que as famílias tivessem estrutura adequada para auxiliá-los, seu processo educacional se estagnou, houve retrocesso nos quesitos sociais e cognitivos. Somente por meio de políticas públicas inclusivas será possível incluir o público-alvo da educação especial no modelo de ensino remoto.

\section{Considerações finais}

É evidente que a pandemia revelou diversos outros aspectos referentes à educação brasileira. Hoje, compreende-se a verdadeira necessidade e importância da entidade escolar, além de aspectos pedagógicos e importância assistencial.

O retorno presencial, dito por muitos a volta ao "normal”, não será algo tão normal assim. O público-alvo da educação especial irá sair novamente de um "casulo" e se submeter em uma nova socialização. A volta virá sobrecarregada de estigmas trazidos pelo distanciamento social e de medidas necessárias para preservação da saúde e da vida. O novo contexto de ensino presencial 
precisará abarcar ainda mais a luta contra desigualdades. Serão necessárias medidas e protocolos que assegurem a participação de todos os estudantes de maneira protegida e eficaz.

Os estudantes da educação especial contaram ainda mais com o apoio da família durante o ensino remoto emergencial. Esse contexto fortaleceu o vínculo entre professor e família, sendo um ponto positivo em relação à Educação Inclusiva. Essa aproximação entre família e escola é muito benéfica para o público-alvo da educação especial.

De certa forma, as marcas da pandemia estarão para sempre interligadas a educação. A pandemia trouxe mudanças importantíssimas e significativas. O ensino remoto quanto o presencial não serão mais vistos separadamente. Assim, é relevante que o estudante de Educação Inclusiva e suas especificidades, sejam considerados. O intuito não é que haja "uma escola" para cada estudante, mas um ensino de qualidade e igualdade para todos, onde as diferenças humanas de cada um sejam valorizadas e respeitadas.

Os temas abordados por esse artigo contribuem para uma educação de qualidade que realmente inclua os estudantes da educação inclusiva na educação básica. Cabe às instituições escolares encontrarem maneiras de atender igualmente, observando a especificidade de cada um, dando apoio e suporte necessário. O respeito às diferenças, a participação e o pertencimento sem distinção são a base da educação.

\section{Referências}

ARRUDA, Eucidio Pimenta. Educação remota emergencial: elementos para políticas públicas na educação brasileira em tempos de Covid-19. EmRede, v.7, n.1, p. 257-275, mai. 2020.

BEZERRA, Maria Aparecida Dantas; ARRUDA Graziela Queiroz; SILVA, Joelma Santana Reis. Prática docente do atendimento educacional especializado (AEE): Em tempos remotos e distanciamento social. Anais CONEDU, 2020, Maceió: 2020.

BRASIL. Constituição: República Federativa do Brasil de 1988. Brasília, DF: Senado Federal, 1988.

BRASIL. Ministério da Educação. Lei no 9.394/1996, de 20 de dezembro de 1996. Estabelece as Diretrizes e Bases da Educação Nacional. Brasília: MEC, 1996.

BRASIL. Câmera dos Deputados. Lei ñ 13.146/2015, de 6 de julho de 2015. Institui a Lei Brasileira de Inclusão da Pessoa com Deficiência (Estatuto da Pessoa com Deficiência). Brasília: 2015.

BRASIL. Ministério da Educação. Decreto n 9.057, de 25 de maio de 2017. Regulamenta o art. 80 da Lei $n^{\circ} 9.394$, de 20 de dezembro de 1996, que estabelece as diretrizes e bases da educação nacional. Brasília: MEC, 2017. http://www.planalto.gov.br/ccivil_03/_Ato2015-

2018/2017/Decreto/D9057.htm. 
CURY, Carlos Roberto Jamil; FERREIRA, Luiz Antonio Miguel; FERREIRA, Luiz Gustavo Fabris; REZENDE, Ana Mayra Samuel da Silva. O Aluno com Deficiência e a Pandemia. Instituto Fabris Ferreira, 2020. Disponível em: https:// freemind.com.br/blog/wp-

content/uploads/2020/07/O-aluno-com-defici\%C3\%AAncia-na-pandemia-I.pdf. Acesso em 05/06/2021.

FACHINETTI, Tamiris Aparecida; SPINAZOLA, Cariza de Cássia; CARNEIRO, Relma Urel Carbone. Educação inclusiva no contexto da pandemia: relato dos desafios, experiências e expectativas. Educaşão em Revista, Marília, v. 22, n. 01, p. 151-166, 2021.

FONTES, Lívio Adriano Xavier; POLETO, Simone Sicora. A importância da pesquisa científica no processo de formação superior. Revista FAESF, v. 2, n. 2, p. 85-93, abr./jun. 2018.

FRANCO, Dalva de Souza; GARCIA, Jeane de Jesus Zanetti; LELLI, Eleandra Aparecida; PEDRO, Luciane; VIEIRA, Elisa. Retorno as aulas presenciais no contexto da pandemia: limites e possibilidades. GREPPE, 13 p. set. 2020. Disponível em:

https://www.greppe.fe.unicamp.br/pf-

greppe/retorno_as_aulas_presenciais_no_contexto_da_pandemia_-

_limites_e_possibilidades.pdf. Acesso em 20/05/2021.

GONÇALVES, Sineide; FERREIRA, Bárbara Eduarda Barbosa. A convergência tecnológica e digital, o ensino remoto emergencial e os alunos com TDAH que frequentam os anos finais do ensino fundamental. Texto Livre: Linguagem e Tecnologia, v. 14, n. 1, abr. 2021.

GROSSI, Marcia Gorett Ribeiro; MINODA, Dalva de Souza; FONSECA, Renata Gadoni Porto. O Impacto da pandemia do Covid-19 na educação: reflexos na vida das famílias. Teoria e Prática da Educação, v. 23, n. 3, p. 150-170, set./dez. 2020.

HODGES, Charles B.; MOORE, Stephanie; LOCKEE, Barbara B.; TRUST, Torrey; BOND, Mark Aaron. (2020). The Difference Between Emergency Remote Teaching and Online Learning. Educause Review. Disponível em: http://er.educause.edu/articles/2020/3/the-difference-betweenemergency-remote-teaching-and-online-learning [GS Search]. Acesso em 05/06/2021.

JOYE, Cassandra Ribeiro; MOREIRA, Marília Maia; ROCHA, Sinara Socorro Duarte. Educação a Distância ou Atividade Educacional Remota Emergencial: em busca do elo perdido da educação escolar em tempos de COVID-19. Research, Society and Development, v. 9, n. 7, 2020.

MARCOLLA, Valdinei; KAIM, Luiza Inês; MORO, Tatiele Bolson; CORRÊEA, Ygor. Alunos com necessidades educacionais específicas em tempos de Covid-19: da interrupção das aulas presenciais à implementação de atividades de ensino remoto. Revista Práxis, v. 12, n. 1, dez. 2020.

MEIRELLES, Antônio Flávio Vitarelli et al. COVID-19 e Saúde da Criança e do Adolescente. Instituto Nacional de Saúde da Mulher, da Criança e do Adolescente Fernandes Figueira (IFF/Fiocruz), 2020. 70 p. Disponível em: https://portaldeboaspraticas.iff.fiocruz.br/wpcontent/uploads/2020/08/COVID-19-SAUDE-CRIANCA-ADOLESCENTE.pdf. Acesso em: 20/05/2021.

NETA, Adelaide de Sousa Oliveira; NASCIMENTO, Romária de Menezes; FALCÃO, Giovana Maria Belém. A educação dos estudantes com deficiência em tempos de pandemia de Covid-19: a invisibilidade dos invisíveis. Interacções, n. 54, p. 25-48, 2020. 
SIMÕES, Rita de Cássia da Silva. Educação na pandemia: a realidade do ensino remoto para surdos no município de Pirpirituba/PB. Dissertação de Mestrado, Instituto Federal da Paraíba, João Pessoa, 2020. Disponível em: https:// repositorio.ifpb.edu.br/handle/177683/1192. Acesso em 05/06/2021.

VIEIRA, Márcia de Freitas; SECO, Carlos Manuel. A Educação no contexto da pandemia de COVID-19: uma revisão sistemática de literatura. Revista Brasileira de Informática na Educaşão RBIE, 28, 1013- 1031, 2020. DOI: http://dx.doi.org/10.5753/rbie.2020.28.0.1013.

WERNECK, Guilherme Loureiro; CARVALHO, Marilia Sá. A pandemia de COVID-19 no Brasil: crônica de uma crise sanitária anunciada. Cad. Saúde Pública, v. 36, n. 5, 2020 